REMATEE DE MALES

Campinas-SP, v.39, n.1, pp. 1-25, jan./jun. 2019

\title{
O MUSEU É UM ESPELHO USTÓRIO
}

\section{MUSEUM IS AN USTORIOUS MIRROR}

\author{
Raul Antelo
}

Resumo: "O museu é o espelho colossal onde o homem se contempla, finalmente, sob todos os ângulos, julga-se literalmente admirável e se abandona ao êxtase expresso em todas as revistas de arte" (BATAILLE, 1970, p. 240). De acordo com Georges Bataille (Documents, publicado em 1929), o espelho é uma metáfora do museu como um todo. Uma longa tradição intelectual no pensamento latino-americano (em especial no Chile, de Sarmiento a Lihn) manteve a divisão sujeito/objeto para analisar de que modo as construções materiais, culturais, sociais e políticas funcionam, de ambos os lados dessa relação, na medida em que ambas estão inscritas com histórias e identidades e podem até modificar-se reciprocamente no interior do espaço do museu.

Palavras-chave: formação identitária; experiência de memória; pesquisa acadêmica.

Abstract: "The museum is the colossal mirror in which man, finally contemplating himself in all forms, and finding himself literally an object of wonder, abandons himself to the ecstasy expressed in art magazines." According to Georges Bataille (Documents, 1929), the mirror was a metaphor of the museum as a whole. A long intellectual tradition in Latin American thought (particularly in Chile, from Sarmiento to Lihn) has maintained a subject/object divide to analyze how material, cultural, social and political constructions function on both sides of this relationship as both come inscribed with histories and identities and can also change one another within the space of the museum.

Keywords: Identity Formation; Memorial Experience; Academic Inquiry.

"Entre o Museu e o Livro há uma relação de mútua metáfora. O livro pode ser 'museu imaginário', tal como o museu pode ser 'livro' que conta, em seus testemunhos tangíveis,

1 Professor titular aposentado de Literatura Brasileira do Centro de Comunicação e Expressão, da Universidade Federal de Santa Catarina (UFSC): <antelo@iaccess.com.br>. 
a história de um povo ou de um artista. [...] Quando se dá um desses caos de metáforas mútuas,

é preciso ver qual é o membro operativo, quer dizer, o que torna a metáfora."

(César Aira, 2017, p. 32)

A estética moderna (Hegel, Michelet, Croce, Menéndez y Pelayo, José Veríssimo) é uma estética de museu que a rigor suspende o valor cultual das obras, isto é, sua capacidade performativa de produção de comunidade. Colocado entre parênteses seu fluir temporal, cada obra pode mais facilmente ser contemplada de maneira autônoma. Alimenta-se da noção kantiana de uma arte desinteressada e meramente contemplativa, uma vez que nossa própria existência já não está em jogo na obra. No entanto essa ideia da coleção de peças ímpares, completas em si mesmas, equilibra-se com seu suplemento, as ruínas e a noção de biblioteca, de que inicialmente Flaubert (A tentação de Santo Antônio, Bouvard e Pécuchet) ou, mais tarde, Borges (Ficções), nos fornecem um paradigma. Surge daí a busca da arkhé e do arquivo ou, em outras palavras, a cisão entre a construção fundacional (a nação, a cidadania) e a arqueologia refundadora, o que alimenta um peculiar paradoxo: o Museu emancipa os objetos do seu passado mas, em compensação, fornece uma permanência ideal à unidade política nacional, que se torna cada vez mais coercitiva e normativa. O Museu é o dispositivo que, separando a obra da história, entrega-a à estética, admitindo que, mesmo assim, seu fantasma, os vestígios da verdade histórica, condicione, paradoxalmente, a imanência de sua leitura. Sintomaticamente, em um dos seus fragmentos póstumos, Nietzsche anota que o conhecimento possui a forma da tautologia e é, portanto, vazio. Conhecer pressupõe uma identificação do não igual, do semelhante, o que é algo essencialmente ilógico e equivale a fulminar a literatura comparada, por exemplo, como um absoluto disparate.

Somente por esse trilho adquirimos um conceito, sendo que, depois, agimos como se o conceito "homem" fosse algo real, quando, no entanto, ele é por nós formado mediante a abstração de todos os traços individuais. Pressupomos que a natureza procede de acordo com tal conceito: mas, aqui, a natureza, bem como o conceito, é antropomórfica. A falta de consideração pelo individual fornecenos o conceito e, com isso tem início o nosso conhecimento: no rubricar, nas tabulações de gêneros. A essência das coisas não corresponde, porém, a isso: é um processo de conhecimento que não se coaduna com a essência das coisas. Muitos traços particulares podem definir uma coisa, mas não todas: a igualação desses traços nos dá o ensejo para agrupar muitas coisas sob um só conceito. 
Enquanto portadores de propriedades, produzimos essências e abstrações como causas de tais propriedades. Que uma unidade - como, por exemplo, uma árvore se nos apresente como uma multiplicidade de propriedades, de relações -, eis algo antropomórfico num duplo sentido: antes de mais nada, essa unidade delimitada, "árvore", não existe, trata-se de algo que foi arbitrariamente seccionado (de acordo com o olho, com a forma); e, ademais, nenhuma relação constitui a relação verdadeira e absoluta, senão que é, novamente, colorida antropomorficamente (NIETZSCHE, 2007, pp. 86-87).

\section{O ESPELHO USTÓRIO}

A literatura nacional, tantas vezes comparada a uma árvore (nos anos 1930, em Raízes do Brasil; ainda nos 1970, em "as nossas literaturas latinoamericanas, como também as da América do Norte, são basicamente galhos das metropolitanas", diz Antonio Candido (1987) em "Literatura e subdesenvolvimento"), surge assim como uma investigação tautológica acerca do vazio. Começo, então, a minha reconstrução retrospectiva no Chile. Em abril de 1842, um jornalista e político ali exilado, Domingo F. Sarmiento (1948b, pp. 203-204), argumentava, nas páginas do Mercúrio, que

El hombre de nuestra época en el dédalo de las diversas exigencias de la sociedad en que vive, mitad material, mitad inteligente, busca en la lectura a más de instrucción y recreo, que la materia de ella le interese y toque de cerca, que tenga relación íntima con las cuestiones sociales y políticas de su época, con los hombres, las costumbres, y el país a que pertenece, con la literatura en fin de su idioma que viene a ser como el espejo ustorio en que se reflejan y concretan los rayos de luz que alumbran el mundo intelectual cuya atmósfera respira. $^{2}$

A literatura é um espelho ustório. Esse elogio da ficção se lia numa resenha da revista El Museo de Ambas Américas, título glosado a partir da Revue des Deux Mondes. El Museo é uma publicação "para todos los pueblos americanos" [para todos os povos americanos], porque "nuestra literatura naciente es más bien que nacional, americana” [nossa literatura nascente é mais do que nacional, é americana] (SARMIENTO, 1948a, p.

2 "O homem de nossa época no dédalo das diversas exigências da sociedade na qual vive, metade material, metade inteligente, busca na leitura mais do que instrução e recreação, que a matéria dela lhe interesse e toque de perto, que tenha relação íntima com as questões sociais e políticas de sua época, com os homens, os costumes e o país ao qual pertence, com a literatura, enfim, de seu idioma, que vem a ser como o espelho ustório no qual se refletem e concretizam os raios de luz que iluminam o mundo intelectual cuja atmosfera respira."

Remate de Males, Campinas-SP, v.39, n.1, pp. 1-25, jan./jun. 2019 - 3 
208). Em poucas palavras, o Museu é também um museu de identidades e sociedades. Dois meses depois, junho de 1842 , no mesmo jornal, na resenha "Scènes de la vie privée et publique des animaux. Études de moeurs contemporaines", Sarmiento (1948b) ainda louvaria não só os textos de Balzac, mas, fundamentalmente, "o buril de Grandville", ilustrando esse estudo das paixões humanas de "reputação verdadeiramente europeia", que acabara de ler.

Em poucas palavras, a definição do trabalho literário como museu já nasce, em Sarmiento, sob a proteção de Grandville, artista que acompanhava pari passu os debates científicos da Restauração sobre a incipiente biologia moderna. Ilustram-no suas gravuras para o livro de Pierre Boitard, Le jardin des plantes (1842), ou para seu próprio álbum, Un autre monde (1844), que com escuta aturdita podemos ouvir como notre monde ou mesmo l'autre monde e, em particular, o episódio Une aprèsmidi au Jardin des Plantes, ocasiões que mostram, tal como diagnosticava Nietzsche, que esse espaço se constitui não só pelo conhecimento, mas, fundamentalmente, pela classificação.

Com efeito, o Museu de história natural, espaço muito frequentado sob Charles X e Louis-Philippe, era também objeto de frequentes matérias em L'Illustration, ou Le Magasin Pittoresque; de início, pelo primado epistemológico da botânica e, a seguir, pela ascensão da zoologia como fim da história, no sentido de abandono do conhecimento do visível pelo estudo filosófico do invisível. Foucault mostraria muito bem que a substituição do organismo pela estrutura e da série pelo quadro permitiram arquivar o velho mundo plano, gravado em preto e branco, para substituir por uma nova massa profunda de tempo, à qual se deu o nome renovado de história, versão incipiente da biopolítica contemporânea.

Ora, é nesse mesmo sentido que um nietzscheano como Georges Bataille (1970, pp. 239-240) define o museu, recorrendo, como Sarmiento, à sensibilidade de Grandville:

Grandville esquematizou as relações do continente com o conteúdo nos museus exagerando (ao menos, aparentemente) os vínculos que se estabelecem, provisoriamente, entre os visitados e os visitantes. Do mesmo modo, quando um nativo da Costa do Marfim coloca alguns machados de pedra polida da época neolítica num recipiente cheio de água, banha-se no recipiente e oferenda umas galinhas àquilo que julga serem pedras de trovão (caídas do céu num raio), não faz nada além de prefigurar a atitude de entusiasmo e de profunda comunhão com os objetos que caracteriza o visitante do museu moderno. 
O museu é o espelho colossal onde o homem se contempla, finalmente, sob todos os ângulos, julga-se literalmente admirável e se abandona ao êxtase expresso em todas as revistas de arte.

Pouco antes disso, em junho de 1929, em suas "Notas sobre o cubismo", escritas para o terceiro número de Documents, o coeditor da revista, Carl Einstein, desafiara seus colegas com a ideia de que as noções teóricas mudaram muito, não menos do que as pulgas mudam de dono, de sorte que, para se exercer a crítica, era preciso, em primeiro lugar, escrever a história dos julgamentos estéticos, para pôr ordem esse "museu das terminologias arbitrárias" e começar a discernir as bases dessas noções e desses julgamentos, a fim de podermos verificar se há, de fato, uma hierarquia entre tais valores. Acatando o conselho, um número após a definição bataillana de "Museu" e na sequência de uma matéria sobre "Têtes et crânes", lemos um texto de Roger Vitrac, ilustrado por uma gravura de Grandville, "L'enlèvement des sabines", em que o escritor busca uma correspondência entre as artes, propondo uma divisão entre máscaras de pensamento [masques de pensée] e máscaras de matéria [masques de matière], estas últimas subdivididas em masques de destruction ou de construction [máscaras de destruição ou de construção] e em masques mobiles ou immobiles [máscaras móveis ou imóveis]. Surge, desse modo, uma classificação heteróclita das máscaras construtivas ou desconstrutivas, a saber: 1. a elipse (retrato sem rosto de Matisse); 2 . o pleonasmo (óleo de Van Gogh); 3. o hipérbato ou inversão (Derain); 4. a silepse (Soutine); 5. a regressão (Max Ernst); 6. a repetição (Klee); 7. a aposição (relevos lunares de Van Gogh). A elas se somam seis tropos de máscaras móveis ou imóveis: 1. a metáfora (Grandville); 2. a catacrese (colagens de Picasso, Masson, Picabia, Ernst); 3. a antonomásia (de Chirico); 4. a alegoria (Roy); 5. a metonímia (de Chirico, Ernst, Miró, Klee, Derain); 6. a sinécdoque (Chagall, Man Ray). Grandville seria então a metáfora, "un masque qui découle d'un rapprochement dans la nature mais dont les termes sont supprimés dans l'œuvre d'art" (VITRAC, 1930, p. 362). ${ }^{3}$

Vitrac, alguém que, como Artaud, pertence à estirpe Jarry, não afirma, mas apenas constata, quase patafisicamente, que a arte é singular, embora as Musas (que cuidam das Artes e as preservam no Museu) sejam

3 "[...] uma máscara que deriva de uma aproximação na natureza, mas cujos termos são eliminados na obra de arte". 
múltiplas. Houve, sem dúvida, na época de Sarmiento ou Grandville, classificação. Mas há agora, entre os modernos, hierarquias. Vitrac, autor, não esqueçamos, de Victor ou Les enfants au pouvoir, propõe neutralizálas. Jean-Luc Nancy acredita que uma tal questão, extremamente espinhenta, ainda costuma ser escamoteada para evitar a análise de seu próprio regime, o singular plural da arte, e das artes, aliás, que sempre deixam marcas, mesmo de sua ausência. ${ }^{4}$ Evita-se assim a questão, precisamente, porque se parte, a priori, da ideia de que não estamos no campo da ontologia, mas no de uma tecnologia. ${ }^{5}$ Surge a indagação: a tecnologia, pode ser uma ontologia, ou ao menos pressupô-la? Eis a questão que surrealistas e acefálicos tentam abordar. A saída de Vitrac de desentranhar, a partir das masques, um equivalente dos tropos no campo da visualidade, aproxima-o da filosofia do disfarce do próprio Grandville, como metamorfose incoativa dos seus autômatos e bonecos de pura ilusão.

Ora, Sarmiento nos falava do museu como um espelho ustório, um espelho côncavo, que arde; Bataille, de um espelho colossal. Ambos,

\footnotetext{
4 "As artes enquanto tais não desaparecem na arte sem deixar vestígios" (ADORNO, 1993, p. 225).

5 Nancy (2008, p. 146) postula que as artes se delimitam "mediante una intensificación que separa registros y, a la vez, los irrita o los agita al contacto recíproco. Y así se embarcan en una metaforicidad indefinida de unas a otras, por la que ninguna puede decirse sin recurso a las demás (color sordo, voz colorida, curva blanda, perfume áspero...): mas esta metafórica no se mide por ninguna propiedad común o dominante, y por consiguiente tampoco llega a extinguirse en ella. La metáfora de arte en arte constituye, mucho más, una metamorfosis siempre incoativa, jamás cumplida sino, al contrario, impedida por el privilegio otorgado en cada oportunidad a un registro, un registro constituido, en sí mismo, por un gesto de activación y recorte.// Las artes se sienten unas a otras; no pueden no sentirse: tocan así en todos los aspectos sensiblemente el orden sensato del sentido, que abren desmesurada, insensata, insensiblemente. Pues la diferencia de los sentidos sensibles no es otra que la diferencia en sí del sentido sensato: la no totalización de la experiencia, sin la cual no habría experiencia" [por meio de uma intensificação que separa registros e, ao mesmo tempo, irrita-os ou os agita ao contato recíproco. E assim se embarcam em uma metaforicidade indefinida de umas a outras, pela qual nenhuma pode se dizer sem recurso às demais (cor surda, voz colorida, curva branda, perfume áspero...): mas esta metafórica não se mede por nenhuma propriedade comum ou dominante e, por conseguinte, também não chega a se extinguir nela. A metáfora de arte em arte é antes uma metamorfose sempre incoativa, jamais cumprida, ao contrário, impedida pelo privilégio outorgado em cada oportunidade a um registro, um registro constituído, em si mesmo, por um gesto de ativação e recorte. [...] As artes sentem umas às outras; não podem não se sentir: tocam assim, em todos os aspectos, sensivelmente, a ordem sensata do sentido, que abrem de maneira descomedida, insensata, insensível. Pois a diferença dos sentidos sensíveis não é outra senão a diferença em si do sentido sensato: a não totalização da experiência, sem a qual não haveria experiência].
}

Remate de Males, Campinas-SP, v.39, n.1, pp. 1-25, jan./jun. 2019 - 6 
porém, nele percebem algo da ordem da exceção, que Walter Benjamin, a seguir, viria a tornar um conceito. De fato, "as exposições universais são lugares de peregrinação ao fetiche mercadoria” é a primeira frase do exposé de Benjamin (2009, p. 43) sobre Baudelaire e a modernidade. O museu era, para Sarmiento, dédalo das exigências da sociedade moderna, baudelairianamente, metade material, metade inteligente, de sorte que essa entronização do produto e o consequente apelo da novidade, aquilo que Marx, segundo o próprio Benjamin, chamava de argúcias teológicas da mercadoria, correspondem-se à discrepância entre seu elemento utópico e seu elemento cínico, o estilo cômico-cósmico de Grandville. Benjamin tomou Grandville como um fio condutor de sua conceituação do circuito da mercadoria, mas é bom não esquecer que uma das fontes para tanto foi um artigo de Pierre Mac-Orlan (1934, p. 24), ${ }^{6}$ no qual se destaca que o humor de Grandville sempre trouxe consigo a presença da morte. A ideia é importante, porque não há como conceituar o museu com prescindência da sua relação com o niilismo.

Façamos, com efeito, um pequeno retrospecto. Em 1920, o n. 14 da revista Littérature traz vários epitáfios de Philippe Soupault, alguns dedicados a colegas de fato defuntos, como Arthur Cravan, porém, a maioria, concernente a escritores ainda vivos, como Georges RibemontDessaignes, Francis Picabia, Théodore Fraenkel, Marie Laurencin, Louis Aragon, Paul Éluard, Tristan Tzara e André Breton, personagens todos que levam nomes ilustres e que "ne sont que Philippe Soupault" [são apenas Philippe Soupault], razão pela qual o autor agradece a cada um dos seus amigos aceitarem ser, por alguns momentos, "le reflet d'un autre" [o reflexo de um outro] (SOUPAULT, 1920, p. 8). Algumas páginas à frente, Paul Éluard estampa o prefácio a L'invitation au suicide, do mesmo Soupault, e nele evoca a figura de Grandville, como um obsessivo ritornello, um mantra quase, que Soupault repetiria irrefletidamente e sem pausa:

J. J. Grandville. Un autre monde. Transformations, visions, incarnations, ascensions, locomotions, explorations, pérégrinations, excursions, stations, cosmogonies, fantasmagories, rêveries, folâtreries, facéties, lubies. Métamorphoses, métempsycoses, apothéoses et autres choses (ÉLUARD, 1920, p. 17$) \cdot{ }^{7}$

6 Mac Orlan era atraído pelo conceito de contingência. Ver "Aventure” (ORLAN, 1921, p. 1). 7 "J.J. Grandville. Outro mundo. Transformações, visões, encarnações, ascensões, locomoções, explorações, peregrinações, excursões, estações, cosmogonias, fantasmagorias, sonhos, fantasias, falsificações, enganos. - Metamorfoses, metempsicoses, apoteoses e outras coisas." 
Esse texto de Taxile Delord nos diz que o museu é o lugar das transformações, encantamentos, ascensões, locomoções, explorações, peregrinações, cosmogonias, fantasmagorias, sonhos, disparates, metamorfoses, metempsicoses e apoteoses. Ou seja, espaço heteróclito de visões e sensações. Mais adiante, em outubro de 1923, uma dupla página central, intitulada ERUTARRETIL (transliteração invertida de Littérature, como refletida, justamente, por um espelho, na linha do futuro Anémic cinema, de Duchamp), ensaia uma constelação de 71 precursores do surrealismo, dentre eles, Grandville, nome estampado com letras não menores que Erasmo, Leibniz, Zola ou Charcot (ÉLUARD, 1920, pp. 24-25). Qual o sentido dessa recorrência de Grandville (o museu) na escrita de Bataille, Vitrac ou Benjamin? O museu é o cinema anêmico da modernidade porque Grandville (o museu) teria mostrado aos surrealistas que a filosofia da história e o próprio materialismo dialético cediam espaço em favor de uma filosofia do mimetismo e da sociedade do espetáculo. ${ }^{8}$

Ora, Roger Caillois, pioneiro na teoria do mimetismo e companheiro de Bataille na aventura acefálica, fez, em nome do mimetismo ("l'arrièreplan fabuleux, sinon halluciné" [o esquema fabuloso, ou mesmo alucinado] - CAILLOIS, 2008, p. 232), uma série de restrições ao modelo epistemológico do museu imaginário bem-comportado de André Malraux (1965), incapaz de esconder seu lado testamentário [inventaire]:

Voici l'inventaire general conçu et aménagé dans son économie essentielle: tout le contraire d'une histoire de l'art, plutôt un tableau à entrées multiples des intentions, des continuités, des osmoses, des paroxysmes et des impasses qui en assurent l'unité comme les bifurcations (CAILLOIS, 2008, pp. 131).9

Coincidentemente, ao analisar as instalações de Bill Viola em Ninfas, Agamben nos diz que o musée imaginaire tornou-se musée cinématographique, cinema anêmico, mas, a rigor, a restrição não é nova. Estamos diante do ponto mais alto de uma divergência que remonta aos anos de vanguarda. Tanto Bataille como Caillois aplicaram, em suas

\footnotetext{
8 No fragmento B 2a, 9, das Passagens, Benjamin (2009) anota que um dos textos mais importantes para o esclarecimento das possibilidades excêntricas, revolucionárias e surrealistas da moda, e que estabelece, aliás, a relação do surrealismo com Grandville, é o capítulo sobre a moda em $O$ poeta assassinado, de Apollinaire.

9 "Eis o inventário geral concebido e conduzido na sua economia essencial: o contrário de uma história da arte, antes um quadro de múltiplas entradas das intenções, das continuidades, das osmoses, dos paroxismos e dos impasses que confirmam a unidade como um conjunto de bifurcações."
}

Remate de Males, Campinas-SP, v.39, n.1, pp. 1-25, jan./jun. 2019 - 8 
leituras, os preceitos de seu colega à frente da Documents, o crítico de arte Carl Einstein, que sempre defendeu a ideia de que as figuras ancestrais são um tipo de memória em que a duração ultrapassa a morte, gerando assim um naturalismo sacro que acaba sendo mais sólido do que o dos viventes, porque nos oferece seu Kâ, ou alma de sombra, garantia de efetiva construção tectônica. Para os ingênuos idealistas, o mundo é uma criação divina; porém, com um ceticismo progressivo, vemos que se dissociam não apenas as crenças e as noções abstratas, mas também a vista e a herança visual. $\mathrm{O}$ mundo e os objetos não são mais paradigmas divinos e eternos, mas um pluralismo de espaços específicos, um conjunto de experiências mistas, que podem desencadear as mais variadas reações. Em sua monografia sobre Braque, por sinal, Einstein considera as imagens um "foyer d'énergie", o que se resgata, por exemplo, no livro de Nicolas Calas, como Foyer d'incendie, isto é, a ideia de que o específico de uma obra seria, justamente, seu lado arbitrário e alucinatório, que nos retira da realidade convencional e monótona. Assim, também, em seu verbete sobre o rouxinol para Documents, o mesmo Carl Einstein ([s.d.], p. 117) define a alma como "um museu de signos privados de sentido" e dissimulados sempre atrás da fachada das atualidades, os "documentos". O presente não passa, portanto, de uma máscara.

Sob essa perspectiva, aberta por Einstein e Bataille, Georges Duthuit (2009) empreende, nas reuniões do Colégio de Sociologia, ao início da guerra, uma análise das representações da morte no Ocidente, em que destaca que, sob a alegoria ética, tais representações radicalizam a degradação de um fato geralmente considerado catastrófico, capaz de desencadear, nas culturas ditas primitivas, festas aterrorizantes de carnificina e de embriaguez, que desvendam ao civilizado questões as mais obscuras e as mais dolorosas, uma ontologia dos afetos.

\footnotetext{
O esqueleto dos velhos armários medievais não cessará jamais de obsedar a Europa, suas páginas de contos, seus envoltórios de canções. Retorna ainda nos folhetos de ligas antialcoólicas, nos panfletos antifascistas ou antibolcheviques, substituindo a foice pelo copo de licor ou a metralhadora, em companhia do vampiro de faces cavadas destas publicações do pós-guerra que expunham benevolamente, a fim de poder indicar, nas últimas páginas, uma escolha de endereços indispensáveis, as devastações e as seduções dos amores de um quarto de hora (DUTHUIT, 2009, p. 226).
}

Para evitar que a morte se constitua numa simples questão de anemia e de indigência, ou mesmo, numa estúpida fixidez, Duthuit propõe considerá-la no seu aspecto físico, de forma que ela só pode ser definida 
em termos da própria vida e da vida em sua expressão a mais tensa possível, pois trata-se de arte, e a mais ardente à qual o homem possa atingir. Ela não é antagônica ou dialética da vida, uma vez que é a própria vida que retorna irreconhecível. Dentre os modernos, destaca-se, assim, Goya, esse pré-Pasolini, que

[...] transmitirá à posteridade o filme alucinante das orgias de esquartejamentos, de estupros, de empalações, de mutilações atrozes, praticadas, sobre os seus, pelos soldados de Napoleão, ${ }^{10}$ contrariados em suas ideias de emancipação universal, esperando que seus confrades italianos, em nome de outro ideal e munidos de invenções mais eficazes, retomem a frio, como técnicos, a série de execuções em massa, numa escala desmedida.

O romantismo encontra-se, portanto, escorado numa tradição já bem longa de devassidão e de horror. Ele possui com Géricault um representante particularmente aplicado e que uma administração inteligente abastece de cabeças decapitadas, permitindo-lhe assim estudar a domicílio, de uma maneira cotidianamente mais incentivada, os progressos da decomposição. Há muito tempo, isto é feito: o cadáver, objeto de medo para o comum dos homens, de veneração ou de solicitude inquieta, suscitando às vezes acessos de delírio ou de fúria orgíaca, tornou-se, nos ateliês, simples acessório de encenação e de exercício profissional. [...] Certos autores, naturalmente, imputam às suas representações sentimentos indiscutíveis de desespero, de ódio ou de cólera. Falta saber sobre a parte que retorna, no elemento motor e patético de tais obras, à semelhança de um fato realizado, dado a priori, e que, graças a seu caráter de luto e de terror, agindo pelo intermediário da memória, e tal qual a fotografia poderia reproduzi-lo, seria suficiente, a ele próprio, para a exaltação ou transtorno do espectador. Aqui o poder de choque pertenceria sem contestação a estas figuras de cera, mecanicamente reproduzidas, maquiladas segundo a natureza e que mantém os fornecedores da casa Dupuytren no primeiro plano da atualidade funerária. O procedimento da superposição de uma imagem inerte e fixa na lembrança do vivente encontra preciosos acessórios no espaço destas máscaras de couro confeccionadas por Seabrook para substituir suas manchas obscuras, os olhos, os lábios, a palidez e o brilho de uma mulher desejada. Não é proibido pensar que estes espartilhos opacos, fendidos no lugar da boca de uma fina ferida, colocam em movimento, em quem dele faz uso, próximo à pele palpitante e quente que dão a impressão de bruscamente destruir, reservas de atrocidade profunda, permitindo a um casal de cúmplices, um fazendo o papel de carrasco, o outro de vítima, representar, nos dois quadros essenciais da existência, aquele do assassinato e aquele do amor, um jogo revoltante de abraços póstumos (DUTHUIT, 2009, pp. 227-229).

10 Jean-Luc Godard (AS CRIANÇAS, 1993) afirma, em “Crianças brincam de Rússia”, que o cinema foi inventado pelas tropas de Napoleão, no longo inverno de Moscou, lendo imagens projetadas na parede branca da cela onde, derrotadas, foram recluídas. "Depois de Napoleão e Hitler, todas as pessoas inteligentes do Ocidente querem invadir a Rússia. Por quê? Por ser a terra natal da ficção e o Ocidente não sabe mais o que inventar", diz a voz de Godard, na pele do príncipe Mishkin.

Remate de Males, Campinas-SP, v.39, n.1, pp. 1-25, jan./jun. 2019 - 10 
Como se vê, Duthuit coincide com Vitrac e Caillois, porém, não menos com Sarmiento ou Benjamin, na ideia do mimetismo como autêntica estrutura profunda da modernidade. A leitura de Goya encontra assim, aos olhos do genro de Matisse, um equivalente contemporâneo num mural daquele mesmo ano, o Guernica de Picasso, que exibiria a comunidade dos que não têm mais comunidade.

\begin{abstract}
Adotando os mesmos limites, aqueles do indivíduo que trabalha fora do grupo e nada tem, ou muito pouco, a esperar da comunidade, nem Goya nem Picasso não caem nestes extremos. Suas obras divergentes ou complementares unemse para indicar que a antinomia matéria-espírito só poderia se resolver aqui ao preço de um esforço quase inconcebível de conciliação e de ultrapassagem que exigiria, ao mesmo tempo que a suspensão exata, na partida, uma percepção diretamente experimentada, uma tradução desta, finalmente liberta das contingências, ao ponto de permitir à personalidade de um criador engajar-se a fundo, como se nada retivesse mais sua mão, nem sua imaginação, no objeto sempre presente da narração. As próprias dificuldades que dois artistas de tal envergadura e igualmente abandonados à sua sorte individual encontram em exprimir-se, sem reserva, lembram que o sentimento da morte, envolto, na intimidade dos seres, a todos os outros sentimentos, só pertencem à consciência coletiva por uma espécie particular de fenômeno social e que traduzi-lo significa evocar a vida inteira, e sua infinita complexidade. Este instinto social, com suas duas pulsões fundamentais, inversas e combinadas, de procriação e de aniquilamento, sejam talvez os ídolos anônimos da antiga Caldeia, aquelas mais tarde da Índia bramânica e da China budista, aquelas de Bizâncio, enfim, e da cristandade romana, que fornecem às vezes a revelação a mais convincente, indefinível e de uma doçura fulminante (DUTHUIT, 2009, pp. 229-230).
\end{abstract}

Para Duthuit (2009, pp. 231-232), portanto, milênio após milênio, a morte domina, ela própria, as "solenidades do silêncio e da destruição iminente", o que lhe permite concluir que

Se temos crânios entalhados no cristal ou enterrados na turquesa e a obsidiana do México, se a Ásia legou-nos divindades terríveis, yamas carregadores de despedaçados, guirlandas de cabeças, cetros-esqueletos, se conhecemos ainda os tapetes de cadáveres dos reis do Egito e da Mesopotâmia, insignificante caça de uma caça ao inimigo, estas figuras, como os Cristos na cruz da época bizantina ou romana, não passam nunca diante da cena e, mais ou menos fielmente, com mais ou menos grandeza, prendendo-se sempre às ordens de uma liturgia que os invade de todo lado. Elas só intervêm, quando o momento chega, no curso do diálogo incessante que segue entre cada qual e todos, chamados a servir festas das quais os despojos da mortalidade, mesmo que permaneça invisível, dirige as evoluções e os coros. As religiões querem, portanto, manter em contato o mais estreito, até o momento propriamente insustentável no qual o organismo torna-se fétido e cozido, o sobrevivente e o desaparecido. Procurando colocar o defunto na sociedade fictícia dos ancestrais, o que conta, sobretudo, é que 
elas ajudam aqueles que ficam, desmantelados por um atentado cometido em algum deles, constantemente repetido e sempre inexplicável, em reconstituir a sociedade real. Este duplo trabalho de desintegração e de síntese mental, sobre o qual fala Hertz, ${ }^{11}$ deixou obras muito mais duráveis do que os dogmas que dão a impressão de tê-las determinado. O gênio, ao contrário, como o compreendeu e formou a nossa cultura, só visa sua própria libertação, ao preço de habilidades de profissões, aliás, rapidamente reveladas, e só pretende dar aos outros homens, menos dotados, os duvidosos consolos da contemplação e do êxtase. Era fatal que suas composições as mais famosas, representando um mártir já apodrecendo ou uma bacante levada pelo prazer, tenham terminado por alinhar-se nos lugares neutros, habitados pela indiferença, os quais são denominados museus (DUTHUIT, 2009, pp. 231-232).

Em poucas palavras, Georges Duthuit glosa a primitiva definição bataillana de museu: ele é o espelho colossal onde o homem se contempla, finalmente, sob todos os ângulos, e julgando-se literalmente admirável, abandona-se ao êxtase. Antecipa, assim, o argumento de Blanchot (1951): a imagem nega o nada e, além do mais, é o olhar do próprio nada que se deita sobre nós. Em obediência a essa posição, a avaliação do museu imaginário de Malraux, feita por Duthuit, será duríssima. ${ }^{12}$ E sua materialização, não menos paradoxal, já que revela um capítulo central dos intercâmbios simbólicos e a morte. Monumentalizada como efeito Beaubourg, no dizer posterior de Baudrillard (1976, 1991), a estratégia de exibição antológica e retrospectiva dos artistas que conformam o cânone moderno, com o apoio do Museu de Arte Moderna e das Bibliotecas especializadas (para retomarmos a prévia expressão de Caillois (2008, p. 132), "une pléthore qui submerge et décourage" [uma pletora que submerge e encoraja]), ela consola mais do que inquieta, porque faz com que o museu congele a imagem e, em última análise, torne-a transparente. Mas nós, os contemporâneos, não precisamos, como se sabe e padece, de utopias domésticas, senão de heterotopias e heterologias inquietantes, argumentará Didi-Huberman. ${ }^{13}$

11 Robert Hertz (1881-1915) estudou na Ècole Normale Supérieure, onde se formou em Filosofia em 1904. Fez um estágio no Museu Britânico e, a seguir, desenvolveu seu doutorado sob a orientação de Ėmile Durkheim e Marcel Mauss, destacando-se como um brilhante integrante do Année Sociologique, notadamente, por seu estudo "Uma contribuição ao estudo da representação coletiva da morte". Ver também seu ensaio "A preeminência da mão direita: um estudo sobre a polaridade religiosa” (1980).

12 Malraux et son musée", publicado em Les lettrres nouvelles (1954), tese desenvolvida nos três volumes de Le musée inimaginable (1956).

13 'C'est d'atlas que nous avons besoin, aujourd'hui plus que jamais, et non pas de simples albums. Les albums déploient une grande utopie de l'art séparée du monde historique, les atlas

Remate de Males, Campinas-SP, v.39, n.1, pp. 1-25, jan./jun. 2019 - 12 


\section{BACK HOME}

\section{Voltemos ao início. A Santiago do Chile e ao jornal. Um recorte nos inquieta:}

Como los jóvenes de hoy los de 1925 fueron una esperanza, pero la misma que se puede tener en relación a una fuerza políticamente desorganizada. Su aspiración a una revolución integral, no sólo de orden económico y político, sino también estético y moral, se repite ahora en el Gran Rechazo a la sociedad opulenta, en su simpatía por los movimientos revolucionarios del Tercer Mundo en las que han visto la posibilidad de un socialismo nuevo, y en los usos y costumbres de la sociedad marginal de los beatniks y de los hippies. Hoy como ayer la revolución integral ha sido pospuesta, existen la amenaza de lo que llamaba Breton "la divinidad insaciable de la guerra”, el peligro de la perpetuación de regímenes

créent des hétérotopies en opérant par divisions et par montages de domaines habituellement séparés les uns des autres (par exemple le domaine de l'art et celui, plus 'documentaire' et trivial, de l'histoire politique). Comme l'écrivait si bien Michel Foucault à l'orée de son Archéologie des sciences humaines: 'Les utopies consolent: c'est que si elle n'ont pas de lieu réel, elles s'épanouissent pourtant dans un espace merveilleux et lisse; elles ouvrent des cités aux vastes avenues, des jardins bien plantés, des pays faciles, même si leur accès est chimérique. Les hétérotopies inquiètent, sans doute parce qu'elles minent secrètement le langage, parce qu'elles empêchent de nommer ceci et cela, parce qu'elles ruinent d'avance la 'syntaxe', et pas seulement celle qui construit les phrases, - celle moins manifeste qui fait 'tenir ensemble' (à côté et en face les uns des autres) les mots et les choses'. Il y aurait donc quelque chose de la Cité de Dieu dans le Musée imaginaire d'André Malraux. Devant ce pays chimérique, l'historien de l'art peut bien se consoler indéfiniment avec la splendeur des chefs-d'oeuvre qui lui sont présentés. Mais ne doit-il pas s'inquiéter aussi des divisions historiques dont témoigne cette splendeur même?" [É do atlas que precisamos hoje mais do que antes, e não de simples álbuns. Os álbuns exibem uma grande utopia da arte separada do mundo histórico, os atlas criam heterotopias que funcionam por divisões e por montagens de domínios costumeiramente separados uns dos outros (por exemplo o domínio da arte e esse outro mais "documentário" e trivial da história política). Como escrevia muito bem Michel Foucault na Arqueologia das Ciências Humanas: "as utopias consolam eis porque, se elas não têm um lugar real, expandemse, no entanto, no espaço maravilhoso e liso, abrem cidades para amplas avenidas, jardins bem construídos, países fáceis, mesmo que o acesso a eles seja quimérico, as heterotopias inquietam, sem dúvida porque sabotam secretamente a linguagem, porque impedem nomear isto ou aquilo, porque arruínam de cara a 'sintaxe' não apenas a que constrói as frases, o que é menos claro que 'manter juntos' (ao lado e enfrentados, uns aos outros) as palavras e as coisas”. Teria portanto algo de $A$ cidade de Deus no Museu imaginário de André Malraux. Perante esse país quimérico, esse historiador da arte pode se consolar infinitamente com o esplendor das obras primas que lhe são apresentadas. Mas não deve se inquietar pelas divisões históricas que testemunham esse mesmo esplendor?] (DIDI-HUBERMAN, 2013b, pp. 171-172). Ver ainda, do mesmo autor, "Soulèvements poétiques (poésie, savoir, imagination)" e Soulèvements. Catalogue de l'exposition (2016-2017).

Remate de Males, Campinas-SP, v.39, n.1, pp. 1-25, jan./jun. 2019 - 13 
injustos, la esperanza en un renacimiento del marxismo, la tentación de las soluciones místicas o del suicidio (LIHN, 1969, [s.p.]).14

Seu autor, o jovem escritor Enrique Lihn, traça, nessas linhas, sua própria genealogia. Poeta, publicaria, em 1973, seu romance Batman en Chile, em que uma funcionária dos Estados Unidos, Juana Sommers, duela com o herói, chileno de nascimento, embora com impecável formação universitária americana, num desafio inexplicável e estúpido, "como lo sería el cielo si el otro mundo existiera. Como lo es en la tierra el país en que nacimos, Batman" [como seria o céu se o outro mundo existisse. Como o é na terra o país em que nascemos, Batman] (LIHN, 1969, p. 129). ${ }^{15}$ Novamente Grandville e o Império. Curiosamente, a Anarquitetura (1974) de Gordon Matta-Clark, seria reconhecida como a tarefa de um Batman da arte (VALDES URRUTIA, 2016). Pouco depois, Lihn (1976) publicaria seu segundo romance, $A$ orquestra de cristal. O relato finge ser uma monografia sobre uma orquestra, absolutamente elusiva e invisível, que é a única a interpretar a sinfonia Amor absoluto, de Roland de Glatigny. The Crystal Orchestra conserva, porém, o impossível: uma partitura em branco, a música do silêncio, um concerto omisso, sendo ela própria um monstro filarmônico, ápice do esteticismo finissecular,

14 "Como os jovens de hoje, os de 1925 foram uma esperança, mas a mesma que se pode ter com relação a uma força politicamente desorganizada. Sua aspiração a uma revolução integral, não apenas de ordem econômica e política, mas também estética e moral, repetese agora na Grande Recusa à sociedade opulenta, na sua simpatia pelos movimentos revolucionários do Terceiro Mundo, em que viram a possibilidade de um socialismo novo, e nos usos e costumes da sociedade marginal dos beatniks e dos hippies. Hoje como ontem a revolução integral foi postergada, existem a ameaça do que Breton chamava 'a divindade insaciável da guerra', o perigo da perpetuação de regimes injustos, a esperança em um renascimento do marxismo, a tentação das soluções místicas ou do suicídio."

15 Batman encarna "los oscuros y radiantes mitos que estaban en la base de la Gran Sociedad y de su crecimiento incontenible: el Mayflower cargado de profetas y de santos que se arrojaban, con heroica voracidad, a la conquista de la Tierra Prometida, contra los rojos emplumados de su tiempo: el Lejano Oeste atravesado por los disparos de los pioneros contra los enemigos de la libertad y la abundancia para todos; la justa derrota de los estados sureños con que el Señor premiaba el norte industrial, convirtiéndolo en el cuerpo y en el alma del país, y los negocios son los negocios, baby, algo realmente sagrado" [os escuros e radiantes mitos que estavam na base da Grande Sociedade e de seu crescimento irreprimível: o Mayflower carregado de profetas e de santos que se jogavam, com heroica voracidade, à conquista da Terra Prometida, contra os vermelhos emplumados de seu tempo: o Longínquo Oeste atravessado pelos disparos dos pioneiros contra os inimigos da liberdade e a abundância para todos; a justa derrota dos estados sulistas com que o Senhor premiava o norte industrial, convertendo-o no corpo e na alma do país, e os negócios são os negócios, baby, algo realmente sagrado] (LIHN, 1973, pp. 8-9). 
que ilustra, além do mais, o caráter sublime da própria tradição musical, inacabada por definição, e simples inanidade sonora, por vocação. Ao relato - originalmente fragmento de uma carta de Gerardo de Pompiffier, bombeiro e fabricante de pompas, carta essa dirigida ao musicologista Roberto Albornoz, e datada de 1916, em Alexandria, no Egito -, somam-se 64 outras notas que referem e refutam, glosam eglorificam o relato de base, no qual além de Pompiffier, amigo do narrador, e Albornoz, precursor do "surrealismo pudico", atuando, ao mesmo tempo, como apologista mas também detrator da The Crystal Orchestra, aparecem, como figurantes, outros autores, como M. Krüger, Heinrich vön Linderhöfer, Charles Royce, junto aos mais previsíveis Baudelaire, Rimbaud e Mallarmé. Como se isso não bastasse, o narrador recebe a visita de dois jornalistas culturais, seus desdobramentos especulares, Germán Lihn e Enrique Marín, ambos redatores das várias versões do romance La orquesta de cristal, que está sendo lido concomitantemente. Como admite o próprio Lihn (DELGADO; MARTÍNEZ, 1978, p. 11), as crônicas da orquestra de cristal "se reflejan mutuamente distorsionándose entre sí, y esos textos son meros pretextos"16 por meio dos quais os cronistas falam do que calam, despreocupados, em última análise, com o que dizem ou escrevem. A alturas tantas da monografia, com efeito, lemos:

Si la pintura ha sido definida aquí como un silencio apasionado ¿qué perspectiva
puede no abrir la audacia con que, por otra parte, se ha llegado a escribir, o casi,
una poesía sin palabras, una Superpoesía, una Poesía Absoluta? (LIHN, 1976,
p. 31).77

16 "[...] se refletem mutuamente distorcendo-se entre si, e esses textos são meros pretextos". 17 "Se a pintura foi definida aqui como um silêncio apaixonado, que perspectiva pode não abrir a audácia com que, por outro lado, se chegou a escrever, ou quase, uma poesia sem palavras, uma Superpoesia, uma Poesia Absoluta?" Relembremosque, noverbete “Absoluto", do dicionário crítico da Documents, Carl Einstein (1929) definira o absoluto como a soma das compensações da miséria humana. O absoluto é poderoso por ser perfeitamente vazio, por isso mesmo ele representa o cúmulo da verdade. Nada pode ser demonstrado pelo absoluto, porque ele é justamente a verdade suprema que permanece indemonstrável. Dele só vemos os detalhes, os recortes, as montagens. Mas essa impossibilidade de provar o absoluto torna-o paradoxalmente inatacável. É impossível abalar uma mentira que, não tendo objeto, a nada pode ser referida: a mentira, de fato, só pode ser constatada se um objeto não se mostra conforme. Em outras palavras, só há verdade no mimetismo, no disfarce. Por isso as obras de arte são indemonstráveis pelo simples fato de estarem separadas, como o absoluto, do objeto. Einstein aventava, inclusive, à maneira da dépense bataillana, que o absoluto é o maior dispêndio de forças feito pelo homem. Como ele não suporta suas próprias forças, é obrigado a se separar delas para encontrar o equilíbrio, o que configura o paradoxo do movimento parado.

Remate de Males, Campinas-SP, v.39, n.1, pp. 1-25, jan./jun. 2019 - 15 


\section{E, em extensa nota de rodapé, lemos ainda:}

La tendencia a tomar al señor Mallarmé al pie de la letra, torpeza en la que él mismo, con su reconocida sagacidad, nunca incurrió, pues conocía entre otras cosas la autosuficiencia de los símbolos, pudo inducir a errores varios por parte de sus pretendidos discípulos. Así, resulta harto evidente que Roberto Albornoz, escudado o casi en este adverbio - presque - ("Casi" - escribe - "se ha llegado a escribir una poesía sin palabras”) al postular su música del silencio, liberada por $\mathrm{A} \mathrm{B}$ o $\mathrm{C}$ razones de la sonoridad, olvidó esa prudencia adverbial meramente aleatoria. Para pensar una poesía sin sonidos, mera trasposición o metáfora de la poesía absoluta, tuvo que creer, en el fondo, que ésta prescindiría en el momento menos pensado y literalmente de las palabras y que le vide papier que la blancheur défend, terminaría por acceder a su materialización literal. Hasta un punto tal podía descuidarse a sí mismo el entusiasmo de los acólitos, en lo que se refiere a las conclusiones lógicas y/o empíricas de sus alcances: pues el papel desescrito hasta la lisa y llana blancura no es más que un papel en blanco cualquiera, imposible de distinguir de sus infinitos congéneres.

El mal interpretado silencio de la poesía sin palabras o realización de la alusión por medio de la "síntesis de la palabra y el silencio" consta a lo menos en parte importante los centenares de las páginas que le dedicó el autor del Golpe de Dados en las que serían sus obras completas; número irrisorio comparado con la cantidad de páginas en blanco que luego cubrieron en su honor los comentaristas de su escritura. Tanto en ese escrito - "último grito silencioso de esta alma muda y toda agitada de palabras" - como en otros textos que se refieren incidentalmente o en profundidad a la correspondencia de la Musique et les Lettres - para fatalidad de más de algún megalómano - no se trató pues de abandonar el lenguaje ni de sustituir a él una música de las palabras que se limitara a alinearlas o yuxtaponerlas sólo por su eufonía, cacofonía o por alguna de las muchas cualidades exclusivamente fónicas que puedan enumerarse. Los contemporáneos más sensatos del señor Mallarmé no habrían pretendido, por tanto, asistir a la liberación de la música del sonido puro con ocasión de un concierto involuntariamente inaudible como el primero que ofreció la Orquestra de Cristal. Comprendieron que el tan mentado silencio del poeta de los dados arrojados absolutamente al azar, debía interpretarse tanto a la luz de los astros como a la oscuridad sensitiva - "toute chose sacrée qui veut demeurer sacrée s'enveloppe de mystère” - de la idea tradicional de la sugestión que el señor Mallarmé tomó claramente de Baudelaire: (“C'est le propre des oeuvres vraiment artistiques d'être une source inépuisable de suggestions") a la cual parece haber incorporado su repugnancia casi física por la denotación y/o los objetos de uso: "Nommer un objet, c'est supprimer les trois quarts de la jouissance d'un poème, qui est fait du bonheur de deviner peu à peu; le suggérer, voilà le rêve" (LIHN, 1976, pp. 116-118). ${ }^{18}$

18 "A tendência em tomar o senhor Mallarmé ao pé da letra, torpeza na qual ele próprio, com sua reconhecida sagacidade, nunca incorreu, pois conhecia entre outras coisas a autossuficiência dos símbolos, pode induzir a vários erros por parte dos seus pretendidos discípulos. Assim, fica mais do que evidente que Roberto Albornoz, escudado ou quase nesse advérbio - presque - ('Quase' - escreve - 'chegou-se a escrever uma poesia sem 
Ora, o absoluto de uma instituição transparente, The Crystal Orchestra, como se disséssemos The Crystal Museum, não esconde, portanto, sua estrutura bipolar: ele é a superação do estágio mitológico da cultura, em nome da autonomia do moderno, mas ao mesmo tempo configura a maior derrota dessa cultura, porque por essa via o homem cria sua própria servidão, a fidelidade à tradição. Idêntico ao vazio e àquilo que não tem objeto, o absoluto (o Museu) é aqui uma entidade transparente, porém, sublime, que coagula tradição. ${ }^{19}$ Em tempos comunitários, as forças alucinatórias eram a expressão de um grupo social; em tempos modernos, porém, elas só se exercem de forma subjetiva, transgredindo convenções e recebendo, em compensação, prisão e punição. É o que Lihn observa, pouco depois, numa hipótese de refundar uma tradição nacional

palavras') ao postular sua música do silêncio, liberada por A B ou C razões da sonoridade, esqueceu essa prudência adverbial meramente aleatória. Para pensar uma poesia sem sons, mera transposição ou metáfora da poesia absoluta, teve que crer, no fundo, que esta prescindiria, no momento menos pensado e literalmente, das palavras e que le vide papier que la blancheur défend, terminaria por aceder a sua materialização literal. Até um determinado ponto podia descuidar de si mesmo o entusiasmo dos acólitos, no que se refere às conclusões lógicas e/ou empíricas de seus alcances: pois o papel des-escrito até a lisa e plana brancura não é mais do que um papel em branco qualquer, impossível de distinguir de seus infinitos congêneres.// O mal interpretado silêncio da poesia sem palavras ou realização da alusão por meio da 'síntese da palavra e o silêncio' consta ao menos em parte importante as centenas de páginas que lhe dedicou o autor de Lance de dados, nas que seriam suas obras completas; número irrisório comparado com a quantidade de páginas em branco que logo cobriram em sua honra os comentaristas de sua escritura. Tanto nesse escrito - 'último grito silencioso desta alma muda e toda agitada de palavras' - como em outros textos que se referem incidentalmente ou em profundidade à correspondência de Musique et les lettres - para fatalidade de mais de um megalomaníaco - não se tratou, pois, de abandonar a linguagem nem de substituí-la por uma música das palavras, que se limitara a alinhá-las ou justapô-las somente por sua eufonia, cacofonia ou por alguma das muitas qualidades exclusivamente fônicas que se possam enumerar. Os contemporâneos mais sensatos do senhor Mallarmé não teriam pretendido, portanto, assistir à libertação da música do som puro por ocasião de um concerto involuntariamente inaudível, como o primeiro que ofereceu a Orquestra de Cristal. Compreenderam que o tão mencionado silêncio do poeta dos dados lançados absolutamente ao acaso, devia ser interpretado tanto à luz dos astros quanto à escuridão sensitiva - 'toute chose sacrée qui veut demeurer sacrées s'enveloppe de mistère' - da ideia tradicional da sugestão que o senhor Mallarmé tomou claramente de Baudelaire: ('C'est le propre des oeuvres vraiment artistiques d'être une source inépuisable de suggestions') à qual parece ter incorporado sua repugnância quase física pela denotação e/ou os objetos de uso: 'Nommer un objet, c'est supprimer les trois quarts de la jouissance d'un poème, qui est fait du bonheur de deviner peu à peu; le suggérer, voilà le rêve'."

19 "A título de curiosidad: ¡lo que es una tradición!" [A título de curiosidade: o que é uma tradição!] (LINH, 1976, p. 118). 
a partir do vazio que detecta em um dos pintores paisagistas chilenos, ilustrativo do alienado museu imaginário, que Lihn (1979, [s.p.]) intitula “de la chilena pintura historia”, um dos mais conspícuos representantes do pós-impressionismo local:

Los maestros, profesores más bien de Pablo Burchard (1875-1964), fueron Pedro Lira y el pintor oficial español Rafael Alvarez Sotomayor. Entre sus inmediatos compañeros generacionales no hay nombres, creo, memorables. Era algunos años mayor que los integrantes de "la generación del 13". Sólo un artista en "de la chilena pintura historia" se le puede comparar; le sirve de antecedente en el oficio y es, hasta cierto punto, su antípoda: Juan Francisco González.

Don Juan y don Pablo sacan la cara por esa historia durante varias generaciones de pintores que no resisten, ni de lejos, la comparación con ese par de monomaníacos de la pintura como arte. No les haré, sin embargo, el flaco servicio de llamarlos geniales; pero vivieron largamente obsedidos por su oficio, alentando con su obra ejemplo a la secuela de sus imitadores, menos felices que ellos.

En contraposición a la rápida respuesta - “espontánea”, prolija y proliferante - de la pintura de González al estímulo visual, don Pablo hizo una obra quizá menos copiosa y más irregular; pero sea cual fuere el número de cuadros que entre ambos suman, son los mejores productores del llamado paisaje chileno. Absurda atribución del nacionalismo a la geografía, pero en fin (LINH, 1979, [s.p.]). ${ }^{20}$

\section{MAIS UM}

Ricardo Lísias publicou A vista particular em 2016. Seu protagonista, o pintor José de Arariboia, prepara exposição no Museu de Arte do Rio de

20 "Os mestres, ou melhor, professores de Pablo Burchard (1875-1964) foram Pedro Lira e o pintor oficial espanhol Rafael Alvarez Sotomayor. Entre seus companheiros geracionais imediatos não há nomes, acredito, memoráveis. Era alguns anos mais velho que os integrantes da 'geração do 13'. Somente um artista em 'de la chilena pintura historia' pode ser comparado a ele; serve-lhe de antecedente no ofício e é, até certo ponto, seu antípoda: Juan Francisco González.// Dom Juan e dom Pablo dão a cara por essa história durante várias gerações de pintores que não resistem, nem de longe, à comparação com esse par de monomaníacos da pintura como arte. Não lhes farei, no entanto, o débil serviço de chamálos geniais; mas viveram longamente obcecados pelo seu ofício, encorajando com sua obra exemplo a sequela de seus imitadores, menos felizes do que eles.// Em contraposição à rápida resposta - 'espontânea', organizada e proliferante - da pintura de González ao estímulo visual, dom Pablo fez talvez uma obra menos copiosa e mais irregular; mas, seja qual for o número de quadros que ambos somam entre si, são os melhores produtores da chamada paisagem chilena. Absurda atribuição do nacionalismo à geografia, mas enfim". O quarto número da revista Cordinación Artística Latinoamericana (CAL), cuja direção era de Nelly Richard, inclui a tradução parcial do ensaio de Susan Sontag sobre a fotografia, com introdução de Adriana Valdés, um fragmento de Walter Benjamin sobre o conceito de história, além de textos de Diamela Eltit e Jorge Glusberg, entre outros. 
Janeiro, o MAR, justamente na época em que Georges Didi-Huberman nele ministra um curso. $\mathrm{O}$ artista não esconde que a coincidência pode abrir-lhe uma rápida passagem ao Beaubourg. Como, até o VII fragmento da ficção, o narrador só comenta a fortuna crítica do artista, sem entrar nos pormenores da obra nem muito menos reproduzi-la, o fragmento VII, uma página em branco, le vide papier etc., pretende nos mostrar uma tela de Arariboia, que é pormenorizadamente descrita no fragmento seguinte:

A tela reproduzida na página anterior, Cidade brava: mar Brasil, resume a concepção estética de José de Arariboia. As ondas que tornam as águas volumosas têm o mesmo formato (embora espessuras um pouco distintas) das figuras humanas que, com dificuldade, podem ser encontradas na região onde a cidade, saindo a duras penas do mar, se ergue. Dizendo de maneira direta: tudo colabora para que o ser humano fique em último lugar.

Há um jogo entre a tela e o título. Ele ocorre em toda a obra de José de Arariboia, muito elogiada também pela persistência do projeto. Segundo Rodrigo Naves, "estamos diante de um artista paciente, que conhece seus recursos e pretende dispô-los sem precipitação", ${ }^{21}$. Como ele faz parte de uma geração conhecida pela velocidade e constante busca por resultados rápidos, aqui está outro dos choques tão comentados em seu trabalho.

A própria temática revolta e nervosa em contraste com os tons suaves e a delicadeza da pincelada completa o ambiente de tensão que torna José de Arariboia um artista notável entre os vários que surgiram no Brasil nos últimos anos. Tudo isso justifica o ainda pequeno mas já eloquente conjunto de textos sobre ele, o valor de seus quadros e o prestígio do museu que deve abrigar sua primeira exposição individual: O MAR (LÍSIAS, 2016, p. 17).

As ondas saem do mar (a arkhé venusina), e a obra termina no MAR. Esse espelhamento da linguagem demonstra que a literatura contemporânea implica o esvaziamento das categorias estéticas mais corriqueiras. Acostumados a associarmos, analogicamente, literatura e artes plásticas, conformea premissa-ponte Grandville=metáfora, agora nos defrontamos com uma exigência oposta, não perceptiva, que é discursiva na pintura e visual na literatura, de tal sorte que somos obrigados a ler quadros e montagens, em vez de imaginar sentidos e significados. A palavra ganha assim o poder paradoxal de fazer os objetos sumirem de nossa vista ou, quando muito, torná-los desaparecidos. A leitura em termos de montagem, aquilo que, por exemplo, confere à escansão psicanalítica

21 E, em nota de rodapé, lemos uma autorização, obviamente apócrifa: "Cf. NAVES, Rodrigo. Um artista a caminho da maturidade. Em Ilustríssima. Folha de S. Paulo, 25 out., 2015”.

Remate de Males, Campinas-SP, v.39, n.1, pp. 1-25, jan./jun. 2019 - 19 
o tom da singularidade absoluta, próprio da patafísica, traz à tona o singular do sujeito, para que, por sua vez, ele se depare com o elemento dispars (DIDI-HUBERMAN, 2010), aquilo que permanece fora do circuito, sem sentido ou sem função. A “ausência de obra” pode então ser lida, de maneira melancólica (Foucault), como ausência psicótica de laço social, ou de maneira eufórica (Agamben), como ativação da in-operância, isto é, como alternativa emancipatória da sujeição involuntária, mas, em todo caso, volta a velha premissa de Sarmiento perante o Museu de ambas as Américas, a literatura é um espelho ustório.

\section{CODA}

Sou o passeante moderno dos museus: percorro quilômetros de quadros, estátuas, desenhos, documentos etnográficos, folclóricos; proponho-me ora acavalar, ora distinguir os diversos ciclos de cultura, consultar uma outra versão da história indicada pela diversidade de ambientes, classes, tipos, indumentária, a variedade dos estilos da obra de arte, instintiva, ritual, gratuita, inserida num contexto religioso, econômico, político; totalizando uma informação que nos ilumina os caminhos do tempo, desde as incertezas do começo até a plenitude do dia atual e o pressentimento do futuro (MENDES, 1995, p. 1.103).

Desde as suas primeiras obras, como O homem sem conteúdo, até as mais recentes, como Criação e anarquia. A obra na época da religião capitalista, Giorgio Agamben vem sustentando uma crítica implacável à associação entre capitalismo, arte e religião. Relembremos, então, a título conclusivo, o seu diagnóstico em Profanações:

A museificação do mundo é atualmente um dado de fato. Uma após outra, progressivamente, as potências espirituais que definiam a vida dos homens - a arte, a religião, a filosofia, a ideia de natureza, até mesmo a política - retiraramse, uma a uma, docilmente, para o Museu. Museu não designa, nesse caso, um lugar ou um espaço físico determinado, mas a dimensão separada para a qual se transfere o que há um tempo era percebido como verdadeiro e decisivo, e agora já não é. O Museu pode coincidir, nesse sentido, com uma cidade inteira (Évora, Veneza, declaradas por isso mesmo patrimônio da humanidade), com uma região (declarada parque ou oásis natural), e até mesmo com um grupo de indivíduos (enquanto representa uma forma de vida que desapareceu). De forma mais geral, tudo hoje pode tornar-se Museu, na medida em que esse termo indica simplesmente a exposição de uma impossibilidade de usar, de habitar, de fazer experiência.

Por essa razão, no Museu, a analogia entre capitalismo e religião se torna evidente. O Museu ocupa exatamente o espaço e a função em outro tempo reservados ao Templo como lugar do sacrifício. Aos fiéis no Templo - ou aos 
peregrinos que percorriam a terra de Templo em Templo, de santuário em santuário - correspondem hoje os turistas, que viajam sem trégua num mundo estranhado em Museu. Mas enquanto os fiéis e os peregrinos participavam, no final, de um sacrifício que, separando a vítima na esfera sagrada, restabelecia as justas relações entre o divino e o humano, os turistas celebram, sobre a sua própria pessoa, um ato sacrifical que consiste na angustiante experiência da destruição de todo possível uso. Se os cristãos eram "peregrinos", ou seja, estrangeiros sobre a terra, porque sabiam que tinham no céu a sua pátria, os adeptos do novo culto capitalista não têm pátria alguma, porque residem na forma pura da separação. Aonde quer que vão, eles encontrarão, multiplicada e elevada ao extremo, a própria impossibilidade de habitar, que haviam conhecido nas suas casas e nas suas cidades, a própria incapacidade de usar, que haviam experimentado nos supermercados, nos shopping centers e nos espetáculos televisivos. Por isso, enquanto representa o culto e o altar central da religião capitalista, o turismo é atualmente a primeira indústria do mundo, que atinge anualmente mais de 650 milhões de homens. E nada é mais impressionante do que o fato de milhões de homens comuns conseguirem realizar na própria carne talvez a mais desesperada experiência que a cada um seja permitido realizar: a perda irrevogável de todo uso, a absoluta impossibilidade de profanar (AGAMBEN, 2007, pp. 65-66).

Grandville (o museu) e todos aqueles que dele se socorreram (diretamente, como Sarmiento, Bataille, Vitrac e Benjamin, ou mesmo indiretamente, como Lihn ou Lísias) com o intuito de descreverem a modernidade, representam um Jano bifronte que foi obrigado a lidar com "ambas as Américas", a sensível e a suprassensível, graças a uma estratégia também dúplice, de um lado, desmontando os mecanismos de representação, enquanto ação tendente à ordem pública, e, de outro, desbravando uma ética sem homem, frente ao crescente niilismo contemporâneo. Em outras palavras, crítica aos valores recebidos e criação de novos valores de vida, desmistificação e transvaloração conjugadas e reportadas não mais à consciência, porém, a uma arkhé que, sendo arcaica, é também contemporânea e age, portanto, como autêntico $a$ priori histórico.

\section{REFERÊNCIAS}

ADORNO, Theodor W. Teoria estética. Trad. Artur Morão. Lisboa: Edições 70, 1993.

AIRA, César. Continuação de ideias diversas. Trad. J. Wolff. Rio de Janeiro: Papéis Selvagens, 2017.

AGAMBEN, Giorgio. Profanações. Trad. Selvino Assmann. São Paulo: Boitempo, 2007. 
AS CRIANÇAS brincam de Rússia. Direção de Jean-Luc Godard. França, Vega Film, 1993. Filme (1h oomin). Título original: Les enfants jouent à la Russie.

BATAILLE, Georges. Musée. In: Oeuvres complètes I. Pref. Michel Foucault. Paris: Gallimard, 1970, pp. 239-240.

BAUDRILLARD, Jean. L'échange symbolique et la mort. Paris: Gallimard, 1976.

BAUDRILLARD, Jean. O efeito Beaubourg: implosão e dissuasão. In: Simulacros e simulação. Lisboa: Relógio D’água, 1991, pp. 81-101.

BENJAMIN, Walter. Passagens. Orgs. Rolf Tiedemann; Willi Bolle; Olgária Chaim Feres Matos. Trad. Irene Aron e Cleonice P. B. Mourão. Belo Horizonte/São Paulo: Ed. UFMG/Imprensa Oficial, 2009.

BLANCHOT, Maurice. Les deux versions de l'imaginaire. Cahiers de la Pléiade, n. 12, primavera-verão 1951, pp. 115-125.

BLANCHOT, Maurice. As duas versões do imaginário. In: O espaço literário. Trad. Álvaro Cabral. Rio de Janeiro: Rocco, 1987, pp. 255-265.

CAILLOIS, Roger. Images du labyrinthe. Ed. Stéphane Massonet. Paris: Gallimard, 2008.

CANDIDO, Antonio. Literatura e subdesenvolvimento. In: A educação pela noite e outros ensaios. São Paulo: Ática, 1987, pp. 140-162.

DELGADO, Josefina; MARTÍNEZ, Carlos. Cada cual tiene sus ilusiones. [Entrevista a Enrique Lihn]. Punto de Vista, ano 1, n. 4, nov. 1978, p. 11.

DIDI-HUBERMAN, Georges. Atlas ¿Cómo llevar el mundo a cuestas? Madri: Museo Nacional Centro de Arte Reina Sofía, 2010.

DIDI-HUBERMAN, Georges. Atlas ou a Gaia Ciência Inquieta. Trad. Renata Correia Botelho e Rui Pires Cabral. Lisboa: KKYM+EAUM, 2013 .

DIDI-HUBERMAN, Georges. L'Album de l'Art à l'Epoque du "Musée imaginaire". Paris: Hazan, 2013b.

DIDI-HUBERMAN, Georges. Soulèvements poétiques (poésie, savoir, imagination). PoEsie, n. 143, 2013c, 1, pp. 153-157.

DIDI-HUBERMAN, Georges. Soulèvements. Catalogue de l'exposition (2016- 2017) au Jeu de Paume, Concorde. Pref. Marta Gili. Colaborações de Nicole Brenez, Judith Butler, Georges Didi-Huberman, Marie-José Mondzain, Antonio Negri e Jacques Rancière. Paris: Jeu de Paume/Gallimard, 2016.

DUTHUIT, Georges. Malraux et son musée. Les lettrres nouvelles, №.2, maio 1954, pp. 357-384. 
DUTHUIT, Georges. Le musée inimaginable. Paris: Corti, 1956.

DUTHUIT, Georges. Representações da Morte. Trad. Maria José Werner Salles. Boletim de pesquisa NELIC, v. 9, n. 14, fev. 2009, pp. 224-232. [Publicado originalmente como: Représentations de la mort. Cahiers d'Art, 14ème année, n. 3, 1939, pp. 25-40.]

EINSTEIN, Carl. Rossignol. Documents, n. 2, 1929, pp.117-118.

ELUARD, Paul. Attestation. Littérature, n. 14, jun. 1920, p. 17.

ERUTARRETIL. Littérature. Nova série, n. 11-12, 15 out. 1923, pp. 24-25.

HERTZ, Robert. A preeminência da mão direita: um estudo sobre a polaridade religiosa. Religião e Sociedade, n. 6, 1980, pp. 99-128.

LIHN, Enrique. Marcuse y el surrealismo. Las notícias de la Última Hora, 7 jun. 1969, [s.p.].

LIHN, Enrique. Batman en Chile. Buenos Aires: Ediciones de la Flor, 1973.

LIHN, Enrique. La orquesta de cristal. Buenos Aires: Sudamericana, 1976.

LIHN, Enrique. Apostilla a de la chilena pintura historia. CAL, n. 4, 1979, [s.p.].

LÍSIAS, Ricardo. A vista particular. Rio de Janeiro: Alfaguara, 2016.

MAC ORLAN, Pierre. Aventure. Aventure, n. 1, nov. 1921, p. 1.

MAC ORLAN. Grandville le précurseur. Arts et Métiers Graphiques, n. 44, 15 dez. 1934, p. 24.

MENDES, Murilo. Poesia completa e prosa. Ed. Luciana Stegagno Pichio. Rio de Janeiro: Nova Aguilar, 1995.

NANCY, Jean-Luc. Las musas. Trad. Horacio Pons. Buenos Aires/Madrid: Amorrortu, 2008.

NIETZSCHE, Frederich. Sobre verdade e mentira. Ed. e trad. Fernando de Moraes Barros. São Paulo: Hedra, 2007.

SARMIENTO, Domingo Faustino. El museo de ambas Américas. In: Obras completas. Artículos críticos y literarios 1841-1842. Buenos Aires: Luz del Dia, 1948a, pp. 203-204.

SARMIENTO, Domingo Faustino. Scènes de la vie privée et publique des animaux. Études de moeurs contemporaines. In: Obras completas. Artículos críticos y literarios 18411842. Buenos Aires: Luz del Dia, 1948b, pp. 236-240.

SOUPAULT, Philippe. Èpitaphes. Littérature, n. 14, jun. 1920, p. 8. 
VALDÉS URRUTIA, Cecília. Gordon Matta-Clark:un Batmandelarteylasociedad. Mercurio. Artes y Letras, 6 mar. 2016. Disponível em: <http://www.economiaynegocios.cl/ noticias $/$ noticias.. sp? id $=231758>$.

VITRAC, Roger. L'enlèvement des Sabines. Documents, n. 6, 1930, p. 362.

Recebido: 16/01/2019

Aceito: 26/04/2019

Publicado: 1/07/2019

Remate de Males, Campinas-SP, v.39, n.1, pp. 1-25, jan./jun. 2019 - 24 